\title{
Hearing profile of gold miners with and without tuberculosis
}

\section{Corresponding author}

Prof De Wet Swanepoel

Department of Communication Pathology

University of Pretoria

PO Box X20

Hatfield

0028

dewet.swanepoel@up.ac.za

Tel: +27 124202304

Fax: +27 124203517

\section{Co-authors}

Janet Brits, Department of Communication Pathology, University of Pretoria, South Africa Susan Strauss, Ear Institute, Pretoria, South Africa

Zahan Eloff, AngloGold Ashanti, South Africa

Piet Becker, Medical Research Council, South Africa

De Wet Swanepoel, 1) Department of Communication Pathology, University of Pretoria, South Africa, 2) Callie Center for Communication Disorders, University of Texas at Dallas, USA

\section{Keywords}

Tuberculosis, noise-induced hearing loss, hearing profile, TB treatment, associated risk profile

\section{Word Count}

4246 words 


\section{ABSTRACT \\ Objectives}

To compare the hearing of gold miners with and without TB to determine the effect of TB and its associated risk profile on hearing.

\section{Methods}

Gold miners in South Africa were sampled due to the high incidence of Tuberculosis (TB). The audiological and medical surveillance data of 2698 subjects (between the years 2001 and 2009) were analysed in a retrospective cohort design. Hearing thresholds for the air conduction frequencies $(0.5,1,2,3,4,6,8 \mathrm{kHz})$ in both ears were analysed in conjunction with biographic and occupational data. Subjects were divided into three groups, two experimental (Single TB treatment, $n=911$ and Multiple TB treatment, $n=376$ ) and a control group $(n=1411)$. Comparisons between groups included (i) change from baseline to most recent audiogram, (ii) most recent hearing thresholds and (iii) most recent thresholds in a subset of noise exposed (drillers) and unexposed (administrative staff) groups.

\section{Results}

Hearing thresholds for the TB groups (single and multiple treatment) were significantly $(p<0.01)$ elevated compared to those of the control group, after correcting for time between the baseline and most recent audiogram, threshold at baseline and age at test. Pair wise comparisons demonstrated the largest threshold differences between the control and multiple TB group. Changes in mean thresholds across TB treatment groups were independent of noise exposure. Hearing thresholds over time also deteriorated significantly more $(p<0.01)$ in workers with TB (single and multiple treatment) compared to those without TB.

\section{Conclusion}


Gold miners with TB, especially those with more than one incidence of TB, demonstrate significantly poorer hearing thresholds and a more pronounced decline in hearing over time independent of noise exposure. The exact cause is likely to be a complex interaction between TB, including its treatment and associated risk profile.

\section{What this paper adds}

$>$ Primary occupational health threats in gold mining are noise-induced hearing loss (NIHL) and occupational lung diseases (OLD) including Tuberculosis (TB).

$>$ TB is associated with predisposing factors for hearing loss including a high incidence of HIV co-infection, associated opportunistic infections and ototoxic medications.

$>$ This is the first study to demonstrate that gold miners with TB have significantly poorer hearing thresholds independent of noise exposure and a more pronounced decline in hearing over time.

$>$ Gold miners with more than one incidence of TB demonstrate a significantly larger deterioration of hearing thresholds than those with a single incidence of TB.

$>$ Monitoring hearing status in miners with TB should be escalated to prevent hearing loss not primarily related to noise exposure but which may be aggravated by it. 


\section{BACKGROUND}

Although gold's value is highly esteemed, the human cost involved in its mining remains high with certain health concerns connected to its specific occupational environment. $[1,2]$ The primary occupational health threats to gold miners are noise-induced hearing loss (NIHL) and occupational lung diseases (OLD) which include Tuberculosis (TB).[3] Both of these diseases are important health concerns and carry a high social and economic cost. There may also be some interdependence between these diseases with TB and its associated risk profile, which includes a high incidence of human immunodeficiency virus (HIV) co-infection, opportunistic infections and ototoxic medications, predisposing individuals to be more susceptible to hearing loss.

Tuberculosis is a common and deadly infectious disease caused mainly by Mycobacterium tuberculosis. It has been called the perfect expression of an imperfect civilization [4] since a third of the world's population carry the TB bacteria, $10 \%$ of infected individuals catch the disease every year and two million (an estimated 5000 per day) die from it annually.[5] The incidence of TB among employees in the Southern Africa gold mining industry has risen three times faster than those among coal and platinum miners.[6] Exposure to respirable silica dust particles increase the risk for mine workers to contract TB.[4] The high prevalence of HIV in

the mine workers further increases the risk of contracting TB due to immunosuppression.[7] Recent TB case findings indicate that between $85 \%$ and $90 \%$ of current TB cohorts are also infected with HIV.[3,5] 
TB usually attacks the lungs ( $75 \%$ of the cases), but can also affect other parts of the body such as the kidney, spine, brain, lining of the abdominal cavity, lungs and heart, reproductive organs. Extra-pulmonary TB accounts for approximately $25 \%$ of all cases and occurs relatively commonly in miners.[6] Apart from the few case studies mentioning extrapulmanory TB such as Tuberculous Otitis Media [8,9] and Tuberculosis of the middle ear cleft [10], Tuberculous Meningitis [11] and Miliary Tuberculosis [12] leading to a sensorineural hearing loss, no other specific reports could be found on a possible relationship between TB and hearing loss. It is possible that TB in itself or TB treatment and their interactions may contribute to or aggravate the pre-existing risk of hearing loss amongst mine workers. In addition to these risk factors individuals with TB already demonstrate a reduced immune response which may make them more susceptible to develop hearing loss. The effect of free radicals (oxidative stress), and lower levels of antioxidants has also been reported in TB patients.[13] Some TB medications are also known to generate free radicals in the cochlea [14], while the metabolic processes related to noise-induced hearing loss are also related to free radicals in the cochlea leading to cell death.

Treatment for TB includes antibiotics to kill the bacteria, usually applied over extended periods of time to entirely eliminate mycobacteria from the body. The standard first-line regimen (specified by the National TB Control Programme) [15] for active TB is a combination of several antibiotics to reduce the risk of the bacteria developing antibiotic resistance and include Isoniazid, Rifampicin, Pyrazinamide, and Ethambutol for two months (five days/week), and Isoniazid and Rifampicin alone for a further four months (five days/week). In retreatment cases Streptomycin is added to the initial phase regimen.[6,15] None of these antibiotics have 
any reported side effects except for Streptomycin which is highly ototoxic.[15,16,17] Despite the possible risks for hearing loss susceptibility related to TB (especially in conjunction with noise exposure), no relationship has yet been demonstrated between TB and hearing loss.

Individual susceptibility to noise along with the degree of hearing loss varies greatly among individuals, which means that with the same exposure to noise, some individuals develop substantial hearing loss, whereas others develop little or no hearing loss at all.[18,19] Noiseinduced threshold shifts also depend on the interaction between intrinsic and environmental factors.[18] Environmental factors or concurrent and contributing factors may include ototoxic drugs (e.g. Streptomycin), infection or illness (e.g. HIVIAIDS and TB) and age.[18,20] Cochlear ototoxicity proceeds stepwise in the damaging of the cochlear structures - affecting the outer hair cells first followed by the inner hair cells.[21] HIV may also cause hearing changes, possibly due to its neurotropic nature with direct involvement of the eighth cranial nerve. Between $21 \%$ and $49 \%$ of HIV-infected patients have been reported to develop a sensorineural hearing loss, which predominantly involves the higher frequencies.[20] Furthermore the same genes that are responsible for age-related hearing loss are also responsible for NIHL $[18,22,23]$, and the effects of age add linearly to the effects of occupational noise exposure.[23]

TB and its associated risk profile pose a complex interaction that may predispose individuals especially those exposed to occupational noise, to permanent hearing loss. The current study therefore compared the hearing profile of gold miners with and without TB to determine the effect of TB on hearing. 


\section{METHOD}

The current study was conducted at the AngloGold Ashanti goldmine South African Region, where it operates seven wholly owned underground mines situated in two geographical regions on the Witwatersrand Basin. Data from employees working at Mponeng, Savuka and Tautona mines which comprise the West Wits operations near Carletonville in the Gauteng province were used.[3] A research collaboration agreement was reached between the University of Pretoria and AngloGold Ashanti to investigate the effect of TB and TB treatment on the hearing of the gold miners. The study protocol was reviewed and approved by ethics committees at the University of Pretoria and AngloGold Ashanti.

In terms of the Mine Health and Safety Act (MHSA, Act 29 of 1996) Instruction 171 [24] and South Africa National Standards (SANS 10083) [25], it is the responsibility of the employer to establish and maintain a system of medical surveillance for all employees in any working place where the equivalent, continuous A-weighted sound pressure level, normalised to a 8 hour working day/40 hour working week exceeds $85 \mathrm{~dB}(\mathrm{~A})$. The medical surveillance is the direct responsibility of the occupational health (medicine) department and qualified nursingand medical practitioners follow standardised protocols in the conduction of all medical and audiological examinations.[6] Company policy at AngloGold Ashanti gold mines also require that all employees exposed to less than $85 \mathrm{~dB}(\mathrm{~A})$ noise should have their hearing monitored once every three years. These medical surveillance records are stored electronically and were accessed by the mine's occupational health department. All required information was exported to Microsoft Office - this included: a company number, test dates, type of audiogram, thresholds for the air conduction frequencies at $0.5,1,2,3,4,6,8 \mathrm{kHz}$ in both the 
left and right ear, job description, average hearing loss, gender, race, age tested and number of working years. The audiometric records consisted of pure-tone air conduction audiograms for right and left ear respectively. Some audiograms were obtained from a diagnostic evaluation (approximately $30 \%$ of the total number of audiograms), others from a baseline, periodic screening, compensation, monitoring or exit assessments. These differently coded audiograms include threshold data over the same frequency range $(0.5$ to $8 \mathrm{kHz})$ but were conducted at different times and for different reasons. This information was used during the data cleaning process. Information on the workers' TB status and type of TB treatment was only made available after informed consent was obtained from all potential subjects. Company Policy in addition states that every employer exposed to noise levels above $85 \mathrm{~dB}$ (A) must wear hearing protection equipment which are provided and monitored by the mine.

The audiological and medical data of 2698 subjects $(96.7 \%$ male $(n=2607)$ and $3.3 \%$ female $(n=89)$, between the years 2001 and 2009) were analysed by making use of a retrospective cohort design. The relatively large sample sizes decrease the variability between sample statistics which allow better estimates of the true population parameters.[26] All the employees from the mines who were diagnosed with and treated for TB during the 2001 and 2009 period were identified by the Occupational Health personnel at the participating mines. South African miners are one of the few communities in the world in which routine radiography is practiced in order to actively detect TB cases.[6] This forms part of their annual medical surveillance routine, and once TB is detected and confirmed by sputum smears, they are started on treatment. After written consent was received from the subjects the audiogram data of these subjects were made available for the study. A control group was selected from 
the audiogram database of all the mine employees between 2001 and 2009 (approximately 57714 employees, 171441 audiograms) after all records of employees with diagnosed TB were removed. It became compulsory in 2001 to do baseline audiogram testing for all individuals in a workplace who are exposed to noise of $85 \mathrm{~dB}(\mathrm{~A})$ and higher in South Africa [24]. Thus audiogram data used in this study dates back to 2001. The control group (TB negative) was matched with the TB cohort based on their exposure to noise and age at the most recent audiogram test. The subjects who gave consent for the study were divided into two experimental groups based on the treatment regimen (treatment and retreatment groups). Classification was done according to TB status and TB treatment record. The standard first-line regimen [15] for active TB is a combination of several antibiotics which include Isoniazid, Rifampicin, Pyrazinamide, and Ethambutol for two months (five days/week), and Isoniazid and Rifampicin alone for a further four months (five days/week). In retreatment cases Streptomycin is added to the initial phase regimen. TB positive subjects were divided into two experimental groups, i.e. TB single treatment group which meant a single episode of TB, and TB multiple treatment group which meant subjects who had more than one incidence of TB and therefore received Streptomycin. As TB incidence in gold-miners is strongly agedependant with a progressive increase in TB disease rates with rising age $[4,27]$, and age also plays a role in the deterioration of a person's hearing status[18,22]; subjects were chosen over a wider age range (20 - 65 years of age) and matched within each group (control, TB single treatment and TB multiple treatment). Table 1 demonstrates how the control and experimental groups were matched based on their age at the most recent audiogram test and their exposure to occupational noise. In summary there were 1411 subjects in the control group with a mean age of 38,55 years (SD 10,27). In the single TB 
treatment group there were 911 subjects with a mean age of 43.30 years (SD 7.00), and in the multiple TB group there were 376 subjects with a mean age of 44.74 years (SD 6.61). The fact that the subjects' average age in the two experimental groups was higher than that of the subjects in the control group is most likely related to the fact that TB incidence in gold miners is largely age-dependent.[4,27] A small percentage of the subjects were over the age of $50(15 \%)$. To avoid any confounding influence of age in comparisons, 'age at test' was adjusted for during all analyses, using ANCOVA. This analysis of covariance (ANCOVA) is a procedure for comparing mean values of research variables while controlling for the influence of a continuous variable (covariate) (such as age). A sub-set analysis was conducted on two homogenous noise exposure groups (table 4), i) drillers (with known high levels of noise exposure) and the administrative personnel (with no known occupational noise exposure).

Noise exposure levels for subjects were described in terms of a specific occupation with documented homogenous noise exposure levels, e.g. pneumatic rock drill (used in the mines under investigation) equals $\sim 108 \mathrm{~dB}(\mathrm{~A})$.[28] Data received from the occupational health division at the mine, indicated noise exposure levels for drillers ranging between $110 \mathrm{dBA}$ and $133 \mathrm{dBA}$. Noise exposure levels were measured in compliance with Instruction 171 and are performed by using a personal dosimeter worn by the mine worker for the duration of his shift. Administrative personnel were above ground and worked in environments that did not require noise monitoring and protection.

Contact with chemicals/solvents like styrene, xylenes, hydrogen and cyanide in occupational settings like the mining industry may have an ototoxic effect [29], and can act synergistically 
with noise exposure.[30] Exposure data for chemical solvents as a potential confounding factor was not however available for subjects in this study.

Data from the experimental and control groups used for statistical analysis were retrieved from the total available mine audiogram dataset $(\mathrm{N}=57714,171441$ audiograms) after data cleaning. A subset of $26.2 \%$ (61017 audiograms) of the larger dataset was disregarded during data cleaning. Data cleaning included the following: Instances where one subject had more than one audiogram done on the same day or in the same year, only one audiogram per year per subject was kept. Duplicates $(n=3855)$ were removed and audiograms conducted for compensation or diagnosis were retained when they coincided with differently coded audiograms, as the former were conducted after inconsistencies in screening audiograms were found. In the same way baseline audiograms were chosen when exit or other audiograms were available for the same subject during the same year. Audiogram data (in Microsoft Office Excel spreadsheets) was disregarded in all rows where no response (NR) values or error codes were recorded in more than four frequencies in one ear. The reason for this is that the values at these frequencies were important for the calculations of hearing threshold averages. Where NR values were recorded for one or two frequencies (mostly high frequencies), and where results correlated with previous audiogram results (within 10dB's), maximum values $(100 \mathrm{~dB})$ were provided. Audiogram data were furthermore excluded in all cases where one ear had normal threshold values and the other NR values. These results most likely indicated a unilateral functional hearing loss (malingering) as interaural attenuation makes this scenario impossible. Where no date of birth was recorded, the subject could not be assigned to an age group, and as a result the data was excluded. Statistical analysis of 
the data set was performed by means of a statistical analysis system (StataCoro. 2007. Stata Statistical Software: Release 10. College Station, TX: StataCorp LP) for descriptive and inferential statistical analyses. . The hearing parameters used to analyse the hearing status of the subjects included: 1) Mean hearing thresholds across all frequencies $(0.5,1,2,3,4,6,8$ $\mathrm{kHz}$ ) 2) Mean hearing thresholds across frequency categories 3) High frequency hearing thresholds (6 and $8 \mathrm{kHz})$. Standard deviations and 95\% confidence intervals $(\mathrm{Cl})$ were also calculated across frequencies These different analyses were performed to provide an overview of all the hearing thresholds of subjects in the three groups, as well as the decline of the hearing thresholds from the first to the most recent audiogram recorded and the difference between the hearing thresholds for a noise exposed and unexposed group. Lower and higher frequencies were separately analysed to provide a more specific comparison between low and high frequency differences [31], since ototoxic medication as well as noise and age have a greater influence on the higher frequencies.[18,22,23]

Analysis of covariance (ANCOVA) and pair wise comparisons were used to establish whether statistically significant relationships existed between variables. The control and two TB groups were compared with respect to (i) the change from baseline to the most recent audiogram and, (ii) most recent hearing thresholds and (iii) most recent audiogram considering a homogeneous exposure subset of noise exposed (drillers) and unexposed (administrative staff) groups. A two way analysis of co-variance (ANCOVA) within the different TB groups and different frequency groups (high and low frequencies) was utilised. Covariates in the two-way ANCOVA were time since the baseline and most recent audiogram and audiogram threshold value at the baseline. Through controlling for the difference in threshold values at baseline 
and the difference in time lapse between baseline and most recent audiogram between the subjects, it was possible to compare the change in hearing threshold over time for the different experimental and control groups. To detect specific differences when groups were found to be significantly different $(p<0.05)$ in the ANCOVA, pairwise comparisons between groups were done according to Fisher's Least Squares Differences Approach ( $F$ test). Given a null hypothesis and a significance level, the corresponding $F$ test rejects the null hypotheses if the value of the F statistic is large.[32] In the same way mean hearing thresholds of the subjects were investigated for the TB and control groups within the different noise exposure groups by controlling for the age of the different subjects as a confounding variable $[18,33]$ with ANCOVA. All reported means are thus adjusted for the effect of the covariate, in this instance, the age of subjects (Table 3 and 4).

\section{RESULTS}

Figures 1 (a), (b) and (c) present the mean hearing thresholds (crude values) of all frequencies across groups to illustrate the deterioration of hearing from the first to the most recent audiogram recorded (in each group). The average number of years between the first and most recent audiogram recorded for all subjects was 4.9 years. The mean age for the covariate 'age at test' was calculated at 37.6 years for the first audiograms and 42.5 years for the most recent audiograms. Across all groups the differences in hearing thresholds between the first and most recent audiograms were more pronounced in the high frequencies, and left ear hearing thresholds were slightly more affected. Differences between the mean thresholds for the first and most recent audiograms were more pronounced in the two experimental groups than in the control group. 
Table 2 includes the average differences (in $\mathrm{dBHL}$ ) between the first and most recent audiograms across the three groups. After adjusting for time between audiograms and baseline as with respect to the change in the different frequencies for left and right ears from 0-1 (first to most recent audiogram) groups differed significantly $(p, 0.0001)$ and in particular following pair-wise comparison all groups were different from one another for the control single and multiple TB groups respectively across left and right ears for the average low frequency $(0.5,1,2 \mathrm{kHz})$ and high frequency $(3,4,6 \mathrm{kHz})$ threshold categories. Pair wise comparisons (F-test) indicated a significant difference between the single TB and multiple TB treatment groups at the $5 \%$ level of significance for left ears' high frequency category, but no other significant differences were noted between these two groups.

Table 3 provides the average hearing thresholds according to various frequency categories with the standard deviation and $95 \%$ confidence intervals across the three groups after controlling for age at test. Highly significant differences $(p<0.01)$ were evident between the control group and both TB treatment groups across the left and right ears for the average low frequency $(0.5,1,2 \mathrm{kHz})$ and high frequency $(3,4,6 \mathrm{kHz})$ threshold categories. A significant difference was also noted during pair wise comparisons (F-test) between the single TB and multiple TB treatment groups at the $1 \%$ level of significance for left ears and the $5 \%$ level of significance for right ears in the low frequency category.

Narrow $\mathrm{Cl}$ in the presence of large SDs is ascribed to the small Standard Error as a result of the large sample size as noted in the methodology section. There was no significant 
difference present between the two experimental groups for the right ears' high frequency category. Analyses of high frequency thresholds (6 and $8 \mathrm{kHz})$ also revealed a highly significant difference $(p<0.01)$ between the control group and both TB treatment groups. Pair wise comparisons (F-test) indicated a significant difference between the $8 \mathrm{kHz}$ thresholds of the single TB and multiple TB treatment groups at the $1 \%$ level of significance. The difference between the $6 \mathrm{kHz}$ left ears' hearing thresholds for these two experimental groups was at the $5 \%$ level of significance, with no significant differences in the right ears' $6 \mathrm{kHz}$ threshold values. (All pair wise comparisons were calculated once adjustments for age had been done). The $95 \%$ confidence intervals for average thresholds indicate ranges that are significantly different across the three groups for all frequency categories and thresholds.

Table 4 provides the mean hearing thresholds and standard deviations across frequency categories for the most recent audiograms in the drillers vs. administrative staff groups across the three groups. Overall mean thresholds for drillers were more elevated across TB treatment categories compared to admin staff but there was no significant difference between the two groups in relation to changes in threshold across TB treatment groups.

\section{DISCUSSION}

Hearing thresholds for mine workers with TB was significantly poorer than that of a matched control group. The largest differences in hearing thresholds throughout this study were between the control group and the multiple TB group with the smallest differences between the two TB groups. This demonstrates that the presence of TB, which includes its related risk profile, significantly influences the decline hearing thresholds in gold miners. The fact that the 
group with more than one incidence of TB presented with the most elevated hearing thresholds is further support that TB and its associated profile of risks (which include Streptomycin as part of the retreatment regimen) place mineworkers at a significantly increased probability for hearing loss.

The differences in hearing thresholds between the three groups were larger in the high frequencies than in the low frequencies, although the differences in the low frequencies were still significant. This phenomenon of high frequency hearing damage preceding low frequency hearing damage is commonly reported and is attributed to a greater vulnerability of high frequency hair cells in the cochlea.[33,34] This is typical of damage by noise exposure, acoustic trauma, age, ototoxic substances and free radicals.[33,34,35] Previous studies confirmed that when the intrinsic free radical buffering system is altered or inefficient (e.g. by TB/TB medication), then the cochlea may become much more vulnerable to noise as its antibuffering system is compromised.[33,34] As the cochlea is exposed to higher levels of free radicals it can also become more susceptible to the development of age-related hearing loss, as the effect of oxidative stress are damaging to most cells with specific deletions within the mitochondrial DNA, and cells become bio-energetically deficient.[36] Furthermore it is possible that TB might alter the homeostatic mechanisms of the ear in a way comparable to that seen in age-related hearing loss.[37] This causes the aural symptoms such as hearing loss, tinnitus and vestibular fall-outs. The fact that the differences between the low frequencies among the three groups, although smaller were also significant, indicate that TB's effect was visible across the whole frequency range. 
Deterioration of hearing thresholds over time was evident across all three groups (although less in the control group and less in the low frequency categories), indicating that age and continued noise exposure contribute to a decline in the hearing status of gold miners as has been reported previously[18,19]. To avoid these confounding influences, analyses adjusted for age, time of noise exposure and the hearing threshold at the first audiogram. When comparing the difference in hearing thresholds between the two TB groups over time however, these differences became almost insignificant. This serves most probably as another indication that the effect of TB (with its associated risk profile) on hearing is more pronounced than the effect of exposure duration over time. Despite complete medical and noise exposure histories being unavailable for subjects in this study the results is a robust indicator of the link between TB and hearing loss. Across the groups, left ear hearing thresholds were slightly poorer than right ears. This has been reported previously and may suggest a greater vulnerability to develop hearing loss compared to the right ear.[18].

There was no significant difference in mean hearing threshold deterioration between the noise exposed (driller) and unexposed (administrative staff) groups across TB treatment groups. This indicates that elevation of mean thresholds in TB treatment groups was independent of noise exposure. The robust TB effect, irrespective of noise exposure, demonstrate that deterioration of hearing with TB treatment is not primarily due to a synergistic effect between confounding variables such as noise exposure and/or contact with chemical solvents but is directly related to TB and its related risk profile for hearing loss. [29, 30] 
The exact nature of the significant increase in deterioration of hearing thresholds in the TB groups is likely to be a complex interaction between TB, its treatment regimens and the associated risk profile which included HIV co-infection.[12] The effect of HIV and antiretroviral therapy, which has reported ototoxicity in some cases,[20] was not accounted for in this study since information on the HIV status of employees was unavailable. According to current estimates however as many as 85 to $90 \%$ of the TB cohort may have been affected with HIV. $[3,5]$ The role of immune-suppression, opportunistic infections, the neurotropic nature of HIV, tumours, antiretroviral medication, ototoxic medications etc. on the hearing status of the miners must therefore also be considered.[5,20,38] TB status consequently represents a larger group of complex risk factors predisposing affected individuals to progressive hearing loss.[39]

\section{CONCLUSION}

Very little has been reported on the relationship between TB status and hearing loss. Results of the current study are the first to demonstrate a significant relationship between TB and a decrease in hearing thresholds. Gold miners with TB, especially those with more than one incidence of TB, demonstrate significantly poorer hearing thresholds and a more pronounced decline in hearing over time independent of noise exposure. The exact cause is likely to be a complex interaction between TB, including its treatment and associated risk profile. Close monitoring of the hearing status and potential risk exposures in workers with TB should be prioritized to prevent hearing loss not primarily related to noise exposure but which may be aggravated by it. 


\section{REFERENCES}

1. Eisler, R. (2003). Health risks of gold miners: A synoptic review. Environmental Geochemistry and Health, 25(3), 325-345.

2. Amedofu, G. K. (2002). Hearing-impairment among workers in a surface gold mining company in Ghana. African Journal of Health Sciences, 9(1-2), 91-97.

3. AngloGold Ashanti. (2006, 2007, 2008). Annual report, report to society 2006, 2007, 2008. http://www.anglogold.com/subwebs/InformationForlnvestors/Reports06/ReportToSociety06/d efault. htm. (accessed March 2009).

4. Bastian I, Stapeldon R, \& Colebunders R. Current thinking on the management of Tuberculosis. Curr Opin Pulm Med. 2003;9:86-192.

5. World Health Organization (2009). TB/HIV Factsheet. http://www.who.int/tb/challenges/ hiv/factsheet hivtb 2009update.pdf. (accessed November 2010).

6. Guild R, Ehrich RI, Johnston JR, et al. SIMRAC handbook of occupational health practice in the South African mining industry (First ed.). Braamfontein, South Africa: The Safety in Mines Research Advisory Committee. 2001:154-232

7. Sonnenberg P, Glynn JR, Fielding K, et al. How soon after infection with HIV does the risk of tuberculosis start to increase? A retrospective cohort study in South African gold miners. $J$ Infect Dis. 2005;191(2):150-158.

8. Cho Y, Lee H, Kim S, et al. Tuberculous Otitis Media: A clinical and radiologic analysis of 52 patients. The Laryngoscope. 2006;116(6):921-927.

9. Campbell BH, Chatton TB, Chusid MJ, et al. Tuberculous otomatoiditis. WMJ. 1985;84(10):22-24. 
10. Ozcelik T, Ataman M, \& Gedikoglu G. An unusual presentation: Primary Tuberculosis of the middle ear cleft. Tubercle Lung Dis. 1995;76(2):178-179.

11. Kuan C, Kaga $\mathrm{K}$, \& Tsuzuku T. Tuberculous meningitis-induced unilateral sensorineural hearing loss: A temporal bone study. Acta Otolaryngol Orient. 2007;127(5):553557.

12. Stach BA, Westerberg BD, \& Roberson Jr JB. Auditory disorder in central nervous system miliary Tuberculosis: Case report. J Am Acad Audiol. 1998;9(4):305-310.

13. Reddy YN, Murthy SV, Krishna DR, et al. Role of free radicals and antioxidants in Tuberculosis patients. Indian J Tuberc. 2004;51:213-218.

14. Bardien S, de Jong G, Schaaf HS, et al. Aminoglycoside-induced hearing loss: South Africans at risk. SAMJ. 2009;99(6).

15. Hausler H. Tuberculosis, HIV and AIDS, clinical guidelines. National Department of Health, TB/HIV Policy task group. October 2000.

16. de Lima MLLT, Lessa F, Aguiar-Santos AM, et al. Hearing impairment in patients with Tuberculosis from Northeast Brazil. Revista do Instituto De Medicina Tropical De São Paulo. 2006; 48(2):99-102.

17. Hershfield E. Tuberculosis:Treatment. CMAJ. 1999;161(4):405.

18. Śliwińska-Kowalska M, Dudarewicz A, Kotyło $P$, et al. Individual susceptibility to noiseinduced hearing loss: Choosing an optimal method of retrospective classification of workers into noise-susceptible and noise-resistant groups. Int J Occup Med Environ Health. 2006;19(4):235-245.

19. Bovo R, Ciorba A, \& Martini A. Genetic factors in noise-induced hearing loss. Audiol Med. 2000;5(1):25-32. 
20. Bektas D, Martin GK, Stagner BB, et al. Noise-induced hearing loss in mice treated with antiretroviral drugs. Hearing Research. 2008;239(1-2):69-78.

21. Duggal $P$, \& Sarkar M. Audiological monitoring of multi-drug resistant Tuberculosis patients on Aminoglycoside treatment with long term follow-up. BMC Ear Nose Throat Disord. $2007 ; 7(5): 1-7$.

22. Kurmis AP, \& Apps SA. Occupationally-acquired noise-induced hearing loss: A senseless workplace hazard. Int J Occup Med Environ Health. 2007;20(2):127-136.

23. Morita Y, Hirokawa S, Kikkawa Y, et al. Fine mapping of Ahl3 affecting both age-related and noise-induced hearing loss. Biochem Biophys Res Commun. 2007;355(1):117-121.

24. Department of Minerals and Energy. Mine Health and Safety Act (MHSA, Act 29 of 1996). South Africa. 1996.

25. Department of Labour. Compensation for occupational injuries and diseases act, no. 130 of 1993. The determination of permanent disablement resulting from hearing loss caused by exposure to excessive noise and trauma. Circular Instruction No. 171. South Africa. 1993.

26. Lohmeier JH. Law of large numbers. Encyclopedia of Research Design. SAGE Publications. 2010 http://0-www.sage-ereference.com.innopac.up.ac.za/researchdesign/ Article n215.html. (accessed August 2010).

27Corbett EL, Charalambous S, Fielding K, et al. Stable incidence rates of Tuberculosis (TB) among human immunodeficiency virus (HIV)-negative South African gold miners during a decade of epidemic HIV-associated TB. J Infect Dis. 2003;188(8): 1156-1163.

28Phillips JI, Heyns PS, \& Nelson G. Rock drills used in South African mines: A comparative study of noise and vibration levels. Ann Occup Hyg. 2007:51(3):305-310. 
29. Campo P, Maguin K, Gabriel S, et al. Combined exposure to noise and ototoxic substances. European Agency for Safety and Health at Work. 2009 http://osha.europa.eu/en/publications/literature reviews/combined-exposure-to-noise-andototoxic-substances (accessed August 2010).

30. Fuente A, Slade MD, Taylor T, et al. Peripheral and central auditory dysfunction induced by occupational exposure to organic solvents. J Occup Environ Med. 2009:51(10):1202-1211. 31. Picard M, Girard SA, Simard M, et al. Association of work-related accidents with noise exposure in the workplace and noise-induced hearing loss based on the experience of some 240,000 person-years of observation. Accid Anal Prev. 2008:40:1644-1652.

32. Maxwell DL, \& Satake E. Research and statistical methods in communication sciences and disorders (First edition). Canada: Thomson Delmar Learning. 2006:111-112,345$350,412-417$.

33. Le Prell CG, Yamashita D, Minami SB, et al. Mechanisms of noise-induced hearing loss indicate multiple methods of prevention. Hearing Research. 2007;226(1-2):22-43.

34. Sha S, Talor R, Forge A, et al. Differential vulnerability of basal and apical hair cells is based on intrinsic susceptibility to free radicals. Hearing Research. 2001;155(1-2):1-8.

35. Henderson D, Bielefeld EC, Harris, KC, et al. The role of oxidative stress in noise-induced hearing loss. Ear and Hearing. 2006;27(1):1-19.

36. Durackova Z. Some current insights into oxidative stress. Physiological Research. 2010;59(4):459-469.

37. Balboni AL, Bergemann AD, Reidenberg JS, et al. Tuberculosis induced changes to the osseous cranial base and its potential effect on hearing. Anat Rec. 2008;291(5):488-490. 
38. Dias B, Chunderdoojh B, \& Hurkchund H. Effects of HIV on occupational health and safety. SIMRAC report nr. SIM 03-09-05. 2006.

39. Toppila E, Pyykkö I, \& Starck J. Age and noise-induced hearing loss. Scand Audiol. 2001;30(4):236-244. 
Table 1. Distribution of age across control and experimental groups and distribution of the subset of noise exposed (drillers) and unexposed (administrative staff) groups

\begin{tabular}{|c|c|c|c|c|c|}
\hline \multicolumn{2}{|c|}{$\begin{array}{c}\text { Age and Noise } \\
\text { Category }\end{array}$} & Control group & $\begin{array}{l}\text { Single TB } \\
\text { treatment }\end{array}$ & $\begin{array}{c}\text { Multiple TB } \\
\text { treatment }\end{array}$ & Total \\
\hline \multicolumn{6}{|c|}{ Age } \\
\hline \multirow[t]{2}{*}{$<30 y r s$} & $n$ & 346 & 34 & 3 & 383 \\
\hline & $\%$ & 24.5 & 3.7 & 0.8 & 14.2 \\
\hline \multirow[t]{2}{*}{$31-40 y r s$} & $\mathrm{n}$ & 478 & 287 & 98 & 863 \\
\hline & $\%$ & 33.8 & 31.5 & 26.0 & 31.9 \\
\hline \multirow[t]{2}{*}{$41-50 y r s$} & $\mathrm{n}$ & 384 & 447 & 198 & 1,029 \\
\hline & $\%$ & 27.2 & 49.0 & 52.6 & 38.1 \\
\hline \multirow[t]{2}{*}{$51-60 y r s$} & $\mathrm{n}$ & 189 & 142 & 75 & 406 \\
\hline & $\%$ & 13.3 & 15.5 & 19.9 & 15.0 \\
\hline \multirow[t]{2}{*}{$>60 y r s$} & $\mathrm{n}$ & 14 & 1 & 2 & 17 \\
\hline & $\%$ & 0.9 & 0.11 & 0.53 & 0.6 \\
\hline Total & $\mathbf{n}$ & 1,411 & 911 & 376 & 2,698 \\
\hline \multicolumn{6}{|c|}{ Noise subset } \\
\hline Admin staff & $\mathrm{n}$ & 50 & 39 & 11 & 100 \\
\hline Drillers & $\mathrm{n}$ & 116 & 144 & 70 & 330 \\
\hline Total & & 166 & 183 & 81 & 430 \\
\hline
\end{tabular}


Table 2. Change in average hearing thresholds (dB HL) (from the first to the most recent audiogram) across frequency categories (Negative values indicate deterioration in hearing thresholds).

\begin{tabular}{|c|c|c|c|c|c|}
\hline \multicolumn{2}{|c|}{ Hearing threshold category } & \multirow{2}{*}{$\begin{array}{l}\begin{array}{c}\text { Control group } \\
(\mathbf{n}=\mathbf{8 3 4})\end{array} \\
-0.8(9.4)\end{array}$} & \multirow{2}{*}{$\begin{array}{c}\begin{array}{c}\text { Single TB } \\
\text { treatment } \\
(\mathbf{n}=923)\end{array} \\
-2.9(9.9)\end{array}$} & \multirow{2}{*}{$\begin{array}{c}\begin{array}{c}\text { Multiple TB } \\
\text { treatment } \\
(\mathrm{n}=373)\end{array} \\
-3.5(11.2)\end{array}$} & \multirow{2}{*}{$\begin{array}{l}\text { p-value* } \\
p=0.000\end{array}$} \\
\hline $\begin{array}{l}\text { Left average low } \\
(0.5,1,2 \mathrm{kHz})\end{array}$ & mean (SD) & & & & \\
\hline $\begin{array}{l}\text { Right average low } \\
(0,5,1,2 \mathrm{kHz})\end{array}$ & mean (SD) & $-0.7(8.9)$ & $-3.13(11.9)$ & $-2.9(11.8)$ & $p=0.000$ \\
\hline $\begin{array}{l}\text { Left average high } \\
(3,4,6 \mathrm{kHz})\end{array}$ & mean $(\mathrm{SD})$ & $-3.1(10.2)$ & $-7.6(12.1)$ & $-9(13.9)$ & $p=0.000$ \\
\hline $\begin{array}{l}\text { Right average high } \\
(3,4,6 \mathrm{kHz})\end{array}$ & mean (SD) & $-3.2(10.2)$ & $-8.5(13.9)$ & $-7.9(13.9)$ & $p=0.000$ \\
\hline
\end{tabular}

${ }^{*}$ After adjusting for time between audiograms and baseline as with respect to the change in the different frequencies for left and right ears from the first to most recent audiogram, groups differed significantly $(p=0.0001)$ and in particular following pairwise comparison all groups were different from one another for the control single and multiple TB groups respectively across left and right ears for the average low frequency $(0.5,1,2 \mathrm{kHz})$ and high frequency $(3,4,6 \mathrm{kHz})$ threshold categories. 
Table 3. Hearing thresholds (dB HL) across frequency categories for the most recent audiogram

\begin{tabular}{|c|c|c|c|c|c|}
\hline \multicolumn{2}{|c|}{ Hearing threshold category } & \multirow{2}{*}{$\begin{array}{c}\begin{array}{c}\text { Control group } \\
(\mathbf{n}=1411)\end{array} \\
11.2(11.5) \\
{[10.5-11.8]}\end{array}$} & \multirow{2}{*}{$\begin{array}{c}\begin{array}{c}\text { Single TB } \\
\text { treatment } \\
(\mathbf{n}=911)\end{array} \\
15.2(12.5) \\
{[14.4-16]}\end{array}$} & \multirow{2}{*}{$\begin{array}{c}\begin{array}{c}\text { Multiple TB } \\
\text { treatment } \\
(\mathbf{n}=376)\end{array} \\
18.4(18.4) \\
{[17.2-19.7]}\end{array}$} & \multirow{2}{*}{$\begin{array}{l}\text { p-value* } \\
p=0.000\end{array}$} \\
\hline $\begin{array}{l}\text { Left average low } \\
(0.5,1,2 \mathrm{kHz})\end{array}$ & $\begin{array}{c}\text { mean }(\mathrm{SD}) \\
95 \% \mathrm{Cl}\end{array}$ & & & & \\
\hline $\begin{array}{l}\text { Right average low } \\
(0,5,1,2 \mathrm{kHz})\end{array}$ & $\begin{array}{c}\text { mean }(\mathrm{SD}) \\
95 \% \mathrm{Cl}\end{array}$ & $\begin{array}{c}10.9(11.1) \\
{[10.2-11.5]}\end{array}$ & $\begin{array}{c}15.6(13.5) \\
{[14.8-16.4]}\end{array}$ & $\begin{array}{c}18.1(13.4) \\
{[16.9-19.3]}\end{array}$ & $p=0.000$ \\
\hline $\begin{array}{l}\text { Left average high } \\
(3,4,6 \mathrm{kHz})\end{array}$ & $\begin{array}{c}\text { mean }(\mathrm{SD}) \\
95 \% \mathrm{Cl}\end{array}$ & $\begin{array}{c}20.8(16.2) \\
{[19.9-21.6]}\end{array}$ & $\begin{array}{c}28.2(17.5) \\
{[27.1-29.3]}\end{array}$ & $\begin{array}{l}32.3(17.2) \\
{[30.6-34]}\end{array}$ & $p=0.000$ \\
\hline $\begin{array}{l}\text { Right average high } \\
(3,4,6 \mathrm{kHz})\end{array}$ & $\begin{array}{c}\text { mean }(\mathrm{SD}) \\
95 \% \mathrm{Cl}\end{array}$ & $\begin{array}{c}19.7(16.4) \\
{[18.7-20.5]}\end{array}$ & $\begin{array}{c}27.9(18) \\
{[26.8-28.9]}\end{array}$ & $\begin{array}{c}30.6(16.9) \\
{[28.9-32.4]}\end{array}$ & $p=0.000$ \\
\hline Left 6 kHz & $\begin{array}{c}\text { mean }(\mathrm{SD}) \\
95 \% \mathrm{Cl}\end{array}$ & $\begin{array}{c}25.6(18.4) \\
{[24.6-26.6]}\end{array}$ & $\begin{array}{l}32.8(19.4) \\
{[31.5-34]}\end{array}$ & $\begin{array}{c}36.4(19.7) \\
{[34.4-38.3]}\end{array}$ & $p=0.000$ \\
\hline Right 6 kHz & $\begin{array}{c}\text { mean }(\mathrm{SD}) \\
95 \% \mathrm{Cl}\end{array}$ & $\begin{array}{c}24.8(18.2) \\
{[23.9-25.8]}\end{array}$ & $\begin{array}{l}33.2(19.6) \\
{[32-34.4]}\end{array}$ & $\begin{array}{c}35.8(18.9) \\
{[33.9-37.7]}\end{array}$ & $p=0.000$ \\
\hline Left 8 kHz & $\begin{array}{c}\text { mean }(\mathrm{SD}) \\
95 \% \mathrm{Cl}\end{array}$ & $\begin{array}{l}23.4(20.2) \\
{[22.3-24.5]}\end{array}$ & $\begin{array}{c}30.8(21.4) \\
{[29.4-32.2]}\end{array}$ & $\begin{array}{l}36.2(23.2) \\
{[34.1-38.4]}\end{array}$ & $p=0.000$ \\
\hline Right 8 kHz & $\begin{array}{c}\text { mean }(\mathrm{SD}) \\
95 \% \mathrm{Cl}\end{array}$ & $\begin{array}{c}22.8(19.4) \\
{[21.8-23.9]}\end{array}$ & $\begin{array}{l}31.3(21.3) \\
{[30-32.6]}\end{array}$ & $\begin{array}{c}36.2(21.8) \\
{[34.1-38.2]}\end{array}$ & $p=0.000$ \\
\hline
\end{tabular}

* Highly significant differences $(p<0.01)$ were evident between the control group and both TB treatment groups across the left and right ears for the average low frequency $(0.5,1,2 \mathrm{kHz})$ and high frequency $(3,4,6 \mathrm{kHz})$ threshold categories. Analyses of high frequency thresholds $(6$ and $8 \mathrm{kHz})$ also revealed a highly significant difference $(p<0.01)$ between the control group and both TB treatment groups. 
Table 4. Average hearing thresholds (SD) across frequency categories for the most recent audiograms in the noise exposed (drillers) and unexposed (administrative staff) groups

\begin{tabular}{|c|c|c|c|c|c|}
\hline \multicolumn{2}{|c|}{ Hearing threshold category } & \multirow{2}{*}{$\begin{array}{l}\text { Control group } \\
\text { (116 drillers + } \\
\quad 50 \text { admin) } \\
14.9(13.2) \\
9.9(8.6)\end{array}$} & \multirow{2}{*}{$\begin{array}{c}\begin{array}{c}\text { Single TB } \\
\text { treatment } \\
\text { (144 drillers + } \\
\mathbf{3 9} \text { admin) }\end{array} \\
18.9(14.8) \\
17.4(11.1)\end{array}$} & \multirow{2}{*}{$\begin{array}{c}\begin{array}{c}\text { Multiple TB } \\
\text { treatment } \\
\text { (70 drillers + } \\
\mathbf{1 1} \text { admin) }\end{array} \\
22.0(15.7) \\
17.7(11.2)\end{array}$} & \multirow{2}{*}{$\begin{array}{c}\text { p-value* } \\
p=0.826\end{array}$} \\
\hline $\begin{array}{l}\text { Left average low } \\
(0.5,1,2 \mathrm{kHz})\end{array}$ & $\begin{array}{l}\text { Driller } \\
\text { Admin }\end{array}$ & & & & \\
\hline $\begin{array}{l}\text { Right average low } \\
(0,5,1,2 \mathrm{kHz})\end{array}$ & $\begin{array}{l}\text { Driller } \\
\text { Admin }\end{array}$ & $\begin{array}{l}14.1(10.8) \\
10.2(14.1)\end{array}$ & $\begin{array}{l}17.7(12) \\
15.8(10.5)\end{array}$ & $\begin{array}{l}20.3(12.1) \\
17.0(10.6)\end{array}$ & $p=0.704$ \\
\hline $\begin{array}{l}\text { Left average high } \\
(3,4,6 \mathrm{kHz})\end{array}$ & $\begin{array}{l}\text { Driller } \\
\text { Admin }\end{array}$ & $\begin{array}{l}26.2(16.3) \\
19.1(15.6)\end{array}$ & $\begin{array}{l}35.7(17.5) \\
31.0(17.7)\end{array}$ & $\begin{array}{l}37.8(16.9) \\
31.7(12.7)\end{array}$ & $p=0.611$ \\
\hline $\begin{array}{l}\text { Right average high } \\
(3,4,6 \mathrm{kHz})\end{array}$ & $\begin{array}{l}\text { Driller } \\
\text { Admin }\end{array}$ & $\begin{array}{l}25.0(14.4) \\
16.9(16.3)\end{array}$ & $\begin{array}{l}33.2(15.6) \\
31.4(18.5)\end{array}$ & $\begin{array}{l}34.5(16.1) \\
34.7(16.3)\end{array}$ & $p=0.585$ \\
\hline
\end{tabular}

*No significant differences were evident between the mean hearing threshold changes across TB treatment categories for drillers and administrative staff within each of the four frequency categories. 


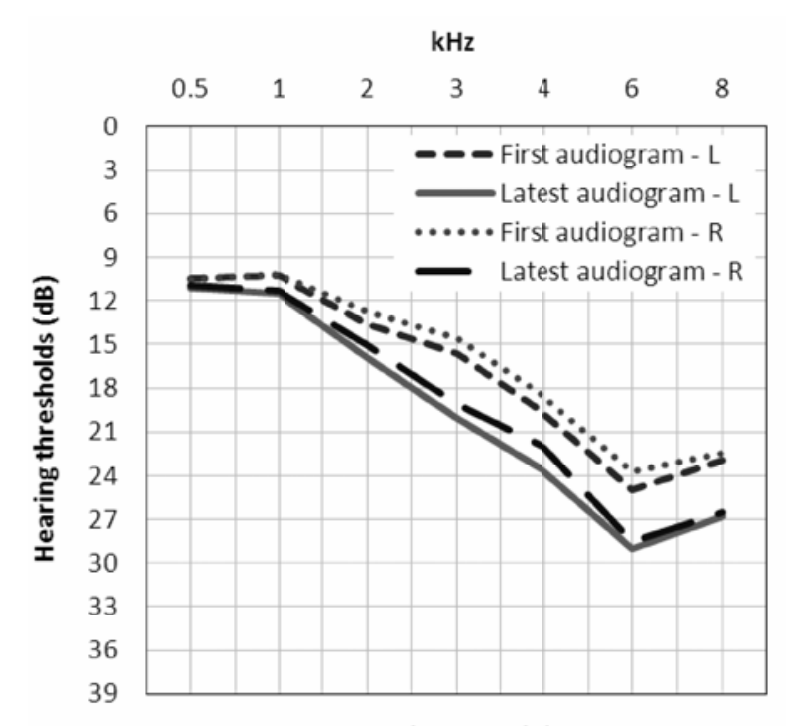

Control group (a)

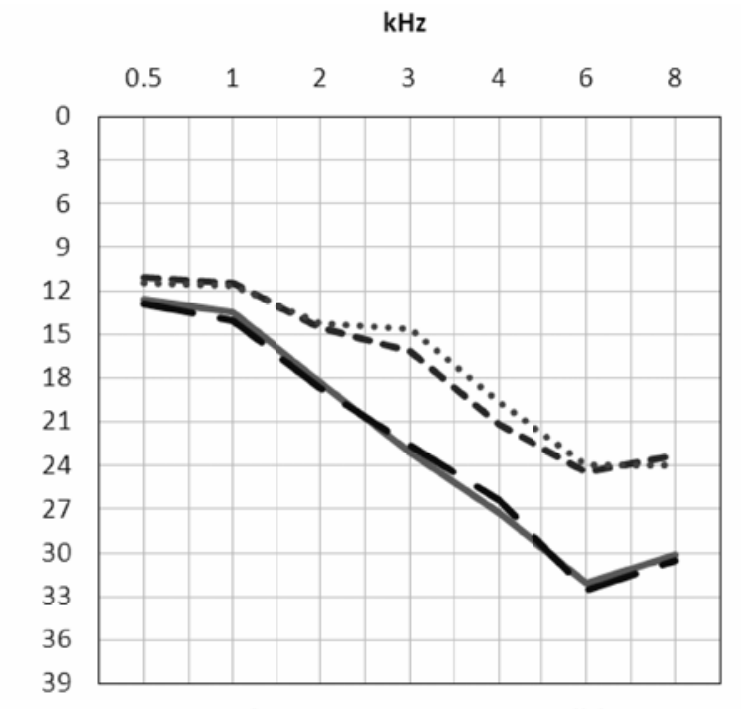

Single TB treatment group (b)

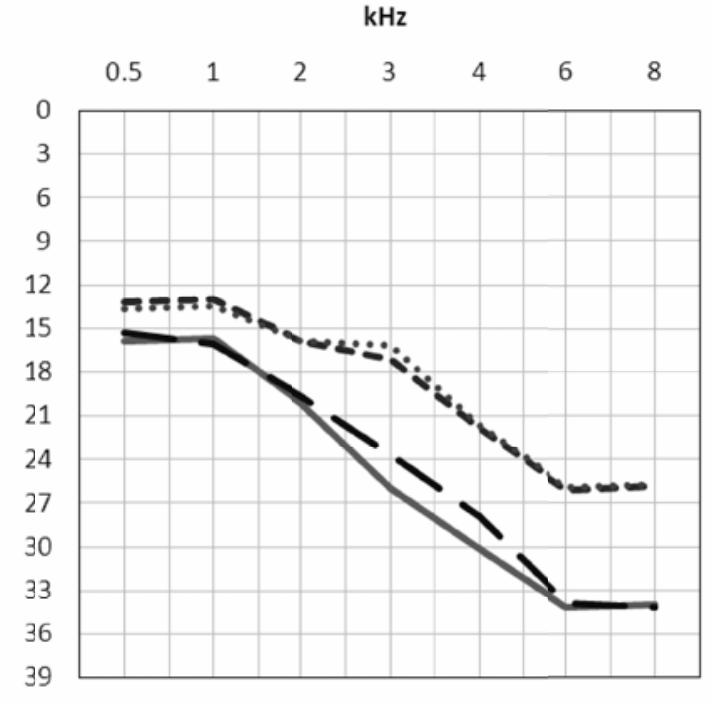

Multiple TB treatment group (c)

Figure 1 Average hearing thresholds for the first and most recent audiograms in the (a) control (b) single TB treatment and (c) multiple TB treatment groups. 